\section{Especificidades do patenteamento no setor farmacêutico: modalidades e aspectos da proteção intelectual}

\author{
Specificities of patent protection in the \\ pharmaceutical industry: modalities and \\ traits of intellectual property
}

\author{
${ }_{1}^{1}$ Instituto Nacional de \\ Tecnologia, Rio de Janeiro, \\ Brasil. \\ 2 Instituto Nacional da \\ Propriedade Industrial, Rio \\ de Janeiro, Brasil. \\ ${ }_{3}$ Centro Federal de Educação \\ Tecnológica Celso Suckow \\ da Fonseca, Rio de Janeiro, \\ Brasil. \\ Correspondência \\ A. H. L. Jannuzzi \\ Instituto Nacional de \\ Tecnologia. \\ Av. Venezuela 82, Rio de \\ Janeiro, RJ 20081-312, Brasil. \\ ahaydee@int.gov.br
}

\begin{abstract}
Different forms of protection for inventions in the pharmaceutical industry point to strategies for the perpetuation of patent protection. Based on a literature review showing the specificities of patenting in the industry, the article provides a brief history of drug patents in Brazil, a discussion of patentable and non-patentable inventions, and the modalities and traits of patent protection that aim to extend the temporary monopoly granted under the patent. Such strategies include patents targeting polimorphs and optical isomers of drugs and drug combinations and specific clinical preparations, increasingly present in the drug patent claims filed by pharmaceutical companies. The study's objective is to discuss the specificities of drug patent claims in order to help develop expertise in the area and discuss the impact of expanding the scope of patent protection. In conclusion, while the tendency to expand towards more a permissive protective scope could produce opportunities for Brazilian national inventors, it could also be harmful to a policy for access to medicines.
\end{abstract}

Drug Patents; Drug Industry; Intellectual Property
Anna Haydée Lanzillotti Jannuzzi 1 Alexandre Guimarães Vasconcellos 2 Cristina Gomes de Souza 3

\section{Introdução}

Propriedade Intelectual é temática debatida internacionalmente envolvendo disputas políticas devido a questões ainda não resolvidas como: definição dos objetos e limites de proteção; conciliação dos interesses de empresas inovadoras e detentores dos direitos de Propriedade Intelectual com os interesses da sociedade; e equilíbrio entre países desenvolvidos - que dominam o conhecimento e fazem uso de mecanismos de proteção - e aqueles que necessitam promover o desenvolvimento para reduzir a pobreza e melhorar a qualidade de vida da população 1 . Em se tratando da indústria farmacêutica, que lida diretamente com a questão da vida, a discussão em torno das patentes farmacêuticas se torna ainda mais complexa e polêmica.

De um lado, existe a retórica de que o monopólio temporário garante o retorno dos investimentos e riscos das atividades de Pesquisa \& Desenvolvimento, dos gastos com o registro do medicamento e da colocação do produto no mercado. Além disso, o processo de desenvolvimento de novos fármacos é longo, mas a expiração da proteção patentária dos medicamentos existentes permitindo a entrada de produtos substitutos no mercado, como medicamentos genéricos, ameaçam a continuidade da vantagem competitiva das empresas inovadoras. $\mathrm{O}$ valor da proteção patentária não pode ser subestimado pelas empresas que perdem cerca de $80 \%$ de seus 
rendimentos com a substituição por genéricos quando as patentes expiram ${ }^{2}$. Outra razão que leva a indústria farmacêutica a proteger seus inventos por meio das patentes é a disparidade entre os altos custos da inovação e os baixos custos da imitação decorrente da facilidade de copiar as moléculas químicas e suas formulações, e do fato de que a produção de medicamentos pode ser realizada em plantas relativamente pequenas. A patente permite, ainda, auferir divisas pelo seu licenciamento. Ainda que o objeto da patente não seja produzido, esta representa uma reserva efetiva de exploração. "Portanto, (...) garante ao seu detentor também a apropriação dos resultados de seu uso, presente ou futuro" 3 (p. 110).

De outro lado, Angell 4 diz que as grandes empresas investem valores módicos em Pesquisa \& Desenvolvimento se comparados às despesas com marketing e administração. A autora acrescenta que a maioria dos "novos" medicamentos constitui-se em variações de produtos existentes no mercado, e que a maior parte dos medicamentos importantes lançados nos Estados Unidos nos últimos anos se baseou em pesquisas financiadas com recursos dos contribuintes e que foram desenvolvidas por instituições acadêmicas, pequenas empresas de biotecnologia e pelo National Institutes of Health. St-Onge 5 reforça essa posição e diz que, apesar de apresentar-se como indústria de risco, a indústria farmacêutica se manteve no topo do ranking das empresas mais rentáveis ao longo da última década do século XX, sendo que, em 2002, o lucro das dez maiores empresas do setor foi maior do que o das demais 490 relacionadas dentre as 500 maiores empresas pela revista Fortune, tendo duplicado sua taxa de retorno no período 1970-1990.

O fato é que o sistema de propriedade industrial tem sido intensamente utilizado pelas indústrias farmacêuticas. Estudos mostram que as patentes são mais importantes para a indústria farmacêutica na apropriação dos benefícios da inovação se comparada a outras indústrias de alta tecnologia 6,7,8. Grabowski 9 estimou que os gastos em Pesquisa \& Desenvolvimento na indústria farmacêutica seriam reduzidos em $64 \%$ no Reino Unido na ausência da proteção patentária, ao passo que nas demais indústrias, a redução seria de apenas $8 \%$.

$\mathrm{Na}$ realidade, muitas patentes são depositadas sem que seu detentor conheça o potencial comercial da invenção e se ela se constituirá num meio efetivo de bloquear a competição. As empresas solicitam patentes para compostos químicos na expectativa de que um deles produza medicamento com venda anual superior a US\$ 1 bilhão (blockbuster). Estrategicamente, as indústrias buscam amplos escopos de proteção de modo que a patente crie um nicho de mercado e as proteja de novos entrantes.

St-Onge 5 mostra que nos últimos trinta anos ocorreu uma mudança radical no setor farmacêutico, passando-se de uma indústria fragmentada para uma indústria centralizada em cerca de 15 multinacionais que necessitam prestar contas aos acionistas e onde o interesse privado prevalece sobre o público. Sobre o preço dos medicamentos, um estudo da Organização Mundial da Saúde (OMS) observou que o preço de um medicamento é fixado em função do preço mais elevado que o mercado pode suportar. O autor cita o fato de que entre 1.556 novas entidades químicas lançadas no mercado entre 1975 e 2004, apenas 21 diziam respeito às doenças negligenciadas, observando-se que a maioria dos investimentos destina-se à produção de $m e$-too ou às chamadas doenças de ricos. Outro aspecto ressaltado é que existem poucas pesquisas sobre fármacos cujas patentes já venceram, substâncias naturais ou para desenvolver medicamentos acessíveis. Destaca ainda a existência de grande desigualdade no acesso aos medicamentos apontando que os Estados Unidos absorvem $43 \%$ do mercado, enquanto a África, por exemplo, consome apenas $1 \%$ dos medicamentos produzidos no mundo.

Levando-se em consideração que o acesso a medicamentos essenciais é um direito fundamental, devendo estes serem tratados como bens públicos, faz-se necessário uma política de medicamentos para orientar e estabelecer os objetivos e estratégias a serem executados, e adequar o setor farmacêutico aos interesses da sociedade. Como a propriedade industrial possui ligação com a elaboração de políticas públicas de saúde, principalmente quanto à implementação de uma política de acesso a medicamentos, o acompanhamento da proteção de patentes farmacêuticas é essencial para que o Governo estabeleça uma política de desenvolvimento industrial para o país integrada à política de saúde. Afinal, no cenário de reconhecimento de patentes, o acesso a medicamentos patenteados pode ocasionar aumento de custos para o sistema de saúde, 10 e estimar seus preços depende da análise de diversos fatores como segmento de mercado e sua divisão pelas empresas, tecnologias existentes, demanda, vendas e preços 11 .

Com o advento da Lei de Inovação 12, Lei $n^{\circ}$. 10.973/04, que determina que as Instituições Científicas e Tecnológicas devem dispor de Núcleo de Inovação Tecnológica com competência para promover a proteção das criações desenvolvidas na instituição, conhecer os aspectos do patenteamento no setor farmacêutico torna-se premente no desenvolvimento de "expertise" para 
alcançar os propósitos de capacitação, obtenção de autonomia tecnológica e desenvolvimento industrial do país na área.

É objetivo do presente artigo elucidar as diversas formas e peculiaridades da proteção dos pedidos de patentes de invenção farmacêutica, de modo a contribuir para a formação de "expertise", com a disponibilização de conhecimentos que poderão fornecer subsídios para que universidades, centros de pesquisa e indústrias nacionais possam obter proteção patentária e benefícios da transferência de tecnologia. Adicionalmente, que elaboradores de políticas públicas e gestores de saúde tanto quanto de ciência, tecnologia e inovação em saúde possam tomar decisões que garantam o acesso da população a medicamentos.

O artigo também visa a colaborar para a discussão sobre o impacto da ampliação dos escopos de proteção das patentes farmacêuticas, por meio das diversas interpretações atribuídas aos requisitos de patenteabilidade.

\section{Concessão de patentes farmacêuticas no Brasil}

O antigo Código da PropriedadeIndustrial (CPI) 13, Lei $n^{\circ}$. 5.772/71, considerava como matéria não patenteável produtos químico-farmacêuticos e medicamentos, e seus processos de obtenção e modificação. A concessão de patentes relativas à tecnologia farmacêutica foi vedada durante 25 anos com o objetivo de desenvolver e proteger a indústria nacional.

A promulgação da Lei $n^{o}$. 9.279/96 (Lei da Propriedade Industrial - LPI) 14, formulada para incorporar resoluções contidas no Acordo dos Direitos de Propriedade Intelectual Relacionados ao Comércio (TRIPS) 15 , revogou essas proibições.

Dentre os dispositivos do TRIPS integrados à LPI, destaca-se o artigo $27 \S 1$ o, que estabeleceu que a proteção patentária deve abranger qualquer invenção em todos os setores tecnológicos, com usufruto dos direitos patentários sem discriminação quanto ao local de invenção e ao fato dos bens serem importados ou produzidos localmente.

A possibilidade do patenteamento de medicamentos fez com que o número de depósitos de patentes classificados como preparações para finalidades médicas aumentasse de 308 em 1995 para 1.281 em 200316.

Outro dispositivo importante do TRIPS foi o aumento do tempo de vigência da patente, de 15 para 20 anos contados a partir da data de depósito. Essa normatização foi estabelecida atenden- do, principalmente, à demanda das indústrias farmacêuticas transnacionais. A justificativa é que o desenvolvimento de novos fármacos leva de 8 a 12 anos, sendo o período de 15 anos de proteção insuficiente para recuperação dos investimentos.

No caso específico da LPI, o parágrafo único do artigo 40 acrescentou ainda que o prazo de vigência da patente de invenção não será inferior a dez anos, a contar da data de concessão. Isso quer dizer que, caso o Instituto Nacional da Propriedade Industrial (INPI) leve mais de dez anos para conceder uma patente, o que já é realidade em alguns casos, esse prazo de atraso será acrescido à vigência da patente.

Além disso, o artigo 230 da LPI permitiu a concessão de patentes a pedidos depositados antes da ratificação do TRIPS - os quais não poderiam ser concedidos pelo antigo CPI 17 - desde que seu objeto não tivesse sido colocado em qualquer mercado, por iniciativa direta do titular ou por terceiros com seu consentimento, nem terem sido realizados sérios e efetivos preparativos para a exploração do referido objeto por terceiros no Brasil. Esses pedidos ficaram conhecidos como "Pipeline".

A Lei $n^{o} .10 .196 / 01$ 18, antiga Medida Provisória 2006/99 reeditada 15 vezes, alterou a LPI. A lei determinou no artigo 229 que pedidos de patentes depositados até 31 de dezembro de 1994 referentes a produtos químico-farmacêuticos e medicamentos, e seus processos de obtenção ou modificação, fossem indeferidos.

$\mathrm{O}$ artigo 229-A da mesma lei, também impôs o indeferimento dos pedidos de patentes de processos de obtenção de produtos químico-farmacêuticos e medicamentos apresentados entre 1o de janeiro de 1995 e 14 de maio de 1997. A Tabela 1 apresenta uma síntese da cronologia criada em relação à concessão de patentes da área farmacêutica.

A Lei $n^{\circ}$. 10.196/01 definiu, ainda, no artigo 229-C que a concessão de patentes para produtos e processos farmacêuticos deveria ter a prévia anuência da Agência Nacional de Vigilância Sanitária (ANVISA). Esse procedimento gerou diversas discussões. A Associação Brasileira de Propriedade Intelectual (ABPI), que congrega empresas, escritórios de agentes de propriedade industrial, escritórios de advocacia e especialistas em propriedade intelectual, editou a Resolução $n^{\circ} .2 / 200019$ afirmando que a medida tratava-se de uma invasão das competências do INPI estabelecidas no artigo 240 da LPI e feria o disposto no artigo 4o da Convenção da União de Paris 20, pois “não poderá ser recusada a concessão de uma patente e não poderá ser uma patente invalidada em virtude de estar à venda o produto patenteado 
Concessão de patentes de produtos e processos químico-farmacêuticos e medicamentos no Brasil.

\begin{tabular}{|c|c|c|c|}
\hline Depósitos (químico- & Pedidos de patentes & Pedidos de patentes depositados & Pedidos de patentes \\
\hline farmacêuticos & depositados até 31 de & entre 1 o de janeiro de & depositados a partir de \\
\hline e medicamentos) & dezembro de 1994 & 1995 e 14 de maio de 1997 & 14 de maio de 1997 \\
\hline Produtos & Não passíveis de proteção & Passíveis de proteção & Passíveis de proteção \\
\hline Processos & Não passíveis de proteção & Não passíveis de proteção & Passíveis de proteção \\
\hline
\end{tabular}

Fonte: Jannuzzi 16.

ou obtido por um processo patenteado sujeita a restrições ou limitações resultantes da legislação nacional". Posteriormente, a ABPI publicou a Resolução $n^{\circ} .16 / 2001$ 21, em que declarou que a ANVISA não poderia apreciar ou rever os requisitos de patenteabilidade - novidade, atividade inventiva e aplicação industrial - devendo se limitar a verificar se o pedido de patente é atentatório à saúde pública.

Na opinião de Barbosa 22, a anuência prévia é válida no sentido de aperfeiçoar o processo de análise das patentes farmacêuticas, mas de todo modo em colaboração e não de decisão, pois atribuir este poder discricionário de negar ou consentir patentes com base no juízo da conveniência e oportunidade da Administração seria incompatível com o artigo 5o, XXIX da Constituição Federal do Brasil. No entanto, se o estatuto da anuência prévia tivesse, tão somente, o propósito de auxiliar no exame técnico sem a preocupação do poder de "não anuir", sua criação seria injustificável, dado que o artigo 31 da LPI já facultava a apresentação, pelos interessados, de documentos e informações para subsidiarem o exame técnico.

O instituto da anuência prévia, considerado de relevância para as políticas nacionais de acesso a medicamentos, também foi implementado na legislação de propriedade intelectual do Paraguai 23,24.

Independente dos limites dos poderes normativos da ANVISA, no que diz respeito à sua anuência prévia, é fato que atualmente existem duas instituições públicas executando trabalhos congêneres. Entretanto, a ANVISA além dos requisitos de patenteabilidade observa os aspectos relevantes à saúde pública, tais como se a concessão da patente implicará na limitação do acesso a medicamentos.

Ressalta-se que, em alguns casos, têm ocorrido divergências de pareceres. Se INPI e ANVISA não chegam a um acordo quanto à concessão da proteção, a patente não é concedida e o processo fica parado no âmbito administrativo do INPI No atual cenário de atraso na concessão de patentes farmacêuticas no país, as indústrias transnacionais, que detêm grande parte dos depósitos na área, poderão ter suas patentes prorrogadas, o que é danoso para uma política de acesso a medicamentos, uma vez que retarda a entrada de produtos genéricos no mercado.

Por outro lado, remédios jurídicos tentam amenizar essa situação, como o licenciamento compulsório previsto na LPI - em casos de abuso do poder econômico, falta de exploração comercial, emergência nacional ou interesse público - e a Exceção Bolar, que trata do uso de uma patente de invenção vigente para pesquisa, sem a necessidade de autorização do titular. Nesse último caso, os atos destinados exclusivamente à produção de informações, dados e resultados de testes, visando à obtenção do registro de comercialização do produto objeto da patente, não se constitui contrafração.

Possibilidades de incorporar uma perspectiva de saúde pública ao exame de patentes incluem o fornecimento de subsídios ao exame antes da concessão da patente e o uso da nulidade administrativa após sua concessão 24 , mecanismos regulamentados nos artigos 31 e 50 a 55 da LPI, respectivamente.

Ainda assim, o monopólio temporário impede a negociação de preços baseada na livre concorrência e a disponibilização de medicamentos patenteados fica condicionada a decisões políticas.

\section{Invenções não-patenteáveis}

O campo das invenções costuma ser delimitado a partir do que não é considerado invenção, visto que esta medida permite aos executores das normas legais decidirem, de maneira não restritiva, sobre a pertinência do enquadramento de novas criações no conceito de invenção 25 . 
As matérias não-patenteáveis são divididas em não-invenções e invenções não-patenteáveis. O TRIPS, nos artigos 27.2, 27.3 e 73, no sentido de proteger a vida ou a saúde humana, meio ambiente e interesses nacionais, definem exceções à patenteabilidade. $\mathrm{O}$ artigo 27.3(a) cita que os países signatários podem considerar como matéria não-patenteável os métodos diagnósticos, terapêuticos e cirúrgicos para o tratamento de seres humanos ou de animais. O Brasil optou por não considerar os referidos métodos como invenções conforme o artigo 10, inciso VIII da LPI.

A legislação brasileira também considera como não-invenção o todo ou parte de seres vivos e materiais biológicos encontrados na natureza, bem como os seus materiais isolados (artigo 10, inciso IX). Este artigo é fundamental para a compreensão da possibilidade de proteção de invenções relacionadas a fitofármacos e fitoterápicos no Brasil. Por ele depreende-se que o extrato de plantas ou moléculas isoladas de plantas não são patenteáveis, mas quando moléculas isoladas ou frações de um extrato de planta passam a constituir uma composição farmacêutica com a presença de outros componentes como adjuvantes e excipientes, a matéria passa a ser considerada como invenção 26 .

A restrição do artigo 10 (IX) também abrange o genoma ou germoplasma de qualquer ser vivo natural e os processos biológicos naturais. A interpretação desse dispositivo é controversa no que diz respeito à patenteabilidade de materiais biológicos produzidos por síntese química ou biotecnológica, quando o produto resultante final é igual à substância de origem natural 25.

Segundo Macedo 27, é considerada invenção a clonagem de uma seqüência de DNA que, após a inserção no hospedeiro adequado, resulta na expressão do produto almejado, apesar de conhecido que, na natureza, existe pelo menos um gene para a codificação de cada proteína. Todavia, nas situações em que no escopo de proteção da invenção encontram-se materiais biológicos idênticos àqueles encontrados na natureza e/ou seus materiais isolados, a invenção não é privilegiável por incidir nas disposições do artigo 10 (IX).

No tocante às invenções não-patenteáveis, o TRIPS determina no artigo 27.3(b) que podese considerar como não patenteáveis plantas e animais, mas excetua microorganismos. Devido à existência de diversas definições para microorganismos 28 , este artigo permite interpretações distintas entre os signatários do acordo. Alguns consideram nessa definição bactérias, fungos, protozoários e células animais e vegetais isoladas. Vasconcellos 26 alerta que países desenvolvidos, além de adotarem essa definição mais abrangente, procuram fazer com que países menos desenvolvidos também a aceitem, de maneira a ampliar o escopo da proteção patentária para inventos que abranjam seres vivos. $\mathrm{O}$ artigo 18 (III) da LPI estabelece como invenções não-patenteáveis o todo ou parte de seres vivos, mas excetua os microorganismos transgênicos que atendam aos requisitos de patenteabilidade e que não sejam mera descoberta.

Desde 2001 está em discussão na Organização Mundial da Propriedade Intelectual (OMPI) o Substantive Patent Law Treaty (SPLT), que trata da harmonização de requisitos como novidade, atividade inventiva e não obviedade, aplicação industrial e utilização, bem como das questões relativas à suficiência descritiva, unidade da invenção, escopo das reivindicações e sua interpretação e definição do estado da técnica ${ }^{29}$. Mediante os assuntos que estão sendo abordados, verifica-se que o SPLT poderá impor modificações nas interpretações dos requisitos de patenteabilidade e alterar matérias consideradas nãopatenteáveis pela atual LPI, caso o Brasil opte por aderi-lo.

\section{Invenções patenteáveis}

No campo das ciências farmacêuticas as invenções podem ser divididas quanto à sua origem em: químicas, como os fármacos obtidos por síntese; biotecnológicas, como vacinas e produção de antibióticos; e aquelas que fazem uso de recursos naturais, por exemplo, fitoterápicos e opoterápicos.

\section{Invenções de origem química}

A proteção dos fármacos é realizada nos estágios iniciais da pesquisa científico-tecnológica ao estabelecer a fórmula química básica do composto, por meio da definição da nova entidade química por "grupo Markush", que representa inúmeros princípios ativos. Um "grupo Markush" é uma expressão genérica para uma classe de substâncias químicas convencionalmente empregadas nas patentes, e consiste de um esqueleto molecular que é substituído por uma ou mais subestruturas variáveis que são acompanhadas da lista de definições destas porções variáveis da molécula 30 . A definição de estruturas químicas por "grupo Markush" foi criada pelo inventor Eugene A. Markush na patente norte-americana US\$1.506.316 concedida em 26 de agosto de 1924.

As reivindicações desse tipo permitem “... ampliar a proteção para possibilidades que, mesmo não tendo sido executadas, são viáveis e visu- 
alizáveis a partir das possibilidades realizadas $e$ descritas no relatório descritivo" 27 (р. 38).

Uma categorização válida para distinguir patentes de fármacos é aquela feita entre "drogas de primeira classe" (que podem originar os blockbusters), a qual foi o invento pioneiro, e as “drogas seguidoras" (me-toos), depositadas geralmente pelos concorrentes com pequenas variações de fórmula química.

Ressalta-se que medicamentos normalmente encontram-se protegidos na primeira patente de invenção do fármaco, dado pela presença de uma reivindicação de composição farmacêutica que, em alguns casos, define as faixas de concentração do agente ativo. Em relação às patentes direcionadas especificamente para medicamentos, observa-se a descrição do invento pelos ingredientes ativos e não-ativos. Estes documentos estão direcionados à proteção de invenções que englobam modificações de formulação sob fundamentação de menores efeitos adversos, menores doses, maior estabilidade e novas formas farmacêuticas que atendam às necessidades de mercado. Nesses casos, o fármaco apresenta-se descrito pela sua denominação genérica, pelo seu nome químico ou classe terapêutica.

\section{Invenções biotecnólogicas}

Biotecnologia é definida pela Organização para a Cooperação e Desenvolvimento Econômico (OCDE) como a aplicação da ciência e tecnologia aos organismos vivos, bem como suas partes, produtos e modelos, para alterar materiais vivos e não-vivos para a produção de conhecimento, bens e serviços 31 . Envolvem vacinas, melhoramentos de sistema de liberação de drogas por meio de proteínas, vetores virais, terapia gênica, nano/micro dispositivos para diagnóstico e outras técnicas biotecnológicas.

Invenções biotecnológicas encerram um produto consistindo ou contendo material biológico ou processo pelo qual este material é produzido. Segundo o Manual de Exame do Escritório de Patentes Europeu (EPO), o termo material biológico significa "qualquer material contendo informação genética e capaz de reproduzir-se ou ser reproduzido em um sistema biológico" 32 (p. 12). Reivindicações do tipo "grupo Markush” também são permitidas na área biotecnológica.

\section{Invenções com produtos de origem natural}

O Brasil é um dos 17 países com elevada biodiversidade e que detém a maior diversidade biológica 33. Nesse contexto, os princípios ativos provenientes do isolamento e identificação de moléculas contidas em plantas, bactérias, fungos e animais com aplicação na produção de medicamentos constituem-se fonte de exploração expressiva.

Na área farmacêutica, plantas e extratos vegetais são importantes devido à utilização das substâncias ativas como protótipos para desenvolvimento de fármacos; como fonte de matérias-primas farmacêuticas para obtenção de adjuvantes; e elaboração de medicamentos fitoterápicos 34 .

Exemplificando, o medicamento contendo o princípio ativo paclitaxel, empregado para vários tipos de câncer tais como de mama e ovariano, foi formulado a partir da extração de uma molécula da casca do Teixo do Pacífico (Taxus brevifolia) na década de 60 . O paclitaxel comercializado como taxol pela Bristol-Myers Squibb vendeu cerca de 9 bilhões de dólares entre 1993-2002, sendo que a diminuição nas vendas ocorreu somente após o ano 2000, parcialmente, devido à entrada da primeira versão genérica do produto 35 .

\section{Modalidades e aspectos do patenteamento no setor farmacêutico}

Rápidas mudanças tecnológicas, redução do ciclo de vida dos produtos, surgimento de novas tecnologias, pressões competitivas e a crescente complexidade das atividades de pesquisa, que cada vez mais necessitam de infra-estrutura sofisticada e equipes multidisciplinares, vêm obrigando organizações farmacêuticas a investirem em inovações incrementais.

As indústrias farmacêuticas têm utilizado estratégias visando à perpetuação da proteção patentária a fim de maximizar seus lucros. Estrutura-se um portfólio de patentes para ser empregado como aliado nas negociações de licenças com concorrentes e parceiros 7,36. O objetivo é estender o prazo de proteção a fármacos que estejam com suas patentes originais prestes a expirar, conseguindo auferir proteção por meio de pequenas inovações incrementais relacionadas ao escopo da invenção original. Dentre essas estratégias destacam-se as "patentes de seleção" e o "2o uso médico".

De acordo com Correa 37 , dentro dos limites permitidos pelas obrigações internacionais, os países podem optar por escopos de proteção distintos, sendo mais ou menos restritivos dependendo de sua posição competitiva no mercado global.

Em 2007, o INPI abriu um ciclo de discussões técnicas sobre patentes farmacêuticas no intuito de aperfeiçoar e desenvolver novas diretrizes de exame $38,39,40,41,42,43,44,45$, dado que as diretrizes 
em vigor 46 não abrangem determinados aspectos das patentes farmacêuticas. O primeiro tema abordado foi a patenteabilidade de formas polimórficas seguido das invenções de "2o uso médico”. As reuniões de discussões técnicas ainda não foram concluídas. O próximo assunto a entrar em pauta será "patentes de seleção".

O exame para concessão de um monopólio deve ser realizado individualmente. Contudo, o estabelecimento de normas mínimas para concessão de patentes diminui a subjetividade das ações decisórias dos examinadores, fornecendo maior transparência e previsibilidade do sistema patentário, o que é relevante para usuários, elaboradores e gestores de políticas públicas de acesso a medicamentos.

\section{Patente de seleção}

"Patente de seleção" pode ser definida como "uma patente sob a qual um único elemento ou um pequeno segmento dentro de um grupo mais abrangente conhecido é 'selecionado' e reivindicado independentemente, baseado numa característica particular não mencionada no grupo mais abrangente" 37.

Uma invenção é considerada como uma seleção quando preenche três requisitos: a seleção é pequena em relação ao objeto conhecido; a seleção não é próxima de qualquer ponto específico revelado nos documentos do estado da técnica, principalmente, nos exemplos; e deve ter um efeito técnico distinto do conhecido 47 .

Dessa forma, patentes com escopos de proteção mais pontuais são descritas sob a argumentação de melhores efeitos técnicos, podendo até mesmo chegar a um único fármaco. Para países em desenvolvimento pode ser vantajoso impedir a patenteabilidade de pequenas modificações subseqüentes de uma nova entidade química, concedendo formas limitadas de proteção, de modo que o inventor inicial possa obter a totalidade do valor de uma patente para o desenvolvimento de um medicamento, sem estender indevidamente o alcance da reivindicação ao patentear cada pequena melhoria ou derivado que surja até que se alcance o produto final 48 .

A título de exemplo, os pedidos de patentes depositados no INPI de derivados de piperazina, úteis no tratamento de depressão, são mostrados na Figura 1. O PI9201624 representa novas entidades químicas reivindicadas por meio de uma "Markush" e o PI9609694, depositado quatro anos depois, é uma seleção de um dos fármacos descritos no primeiro depósito de patente de invenção.

Ponto polêmico da concessão de patentes de seleção reside no fato destas preencherem ou não o requisito de novidade. Alguns especialistas afirmam que o fato do composto estar descrito no "grupo Markush" do pedido original é suficiente para que o dito composto esteja compreendido no estado da técnica. Em oposição, outros especialistas partem do princípio que o composto selecionado estaria revelado, quando descrito especificamente nos exemplos da patente original.

A aceitação das patentes de seleção mostra certa maleabilidade quanto ao requisito de novidade. A novidade absoluta na qual o objeto da patente não pode estar contido no estado da arte 49 passa a ser relativa, uma vez que o composto selecionado faz parte das possibilidades de substituição dos radicais da "patente mãe" (primeira "Markush").

Dentre as patentes de seleção, neste trabalho são destacadas algumas versões específicas: os polimorfos e os isômeros ópticos.

\section{- Polimorfismo}

Alguns fármacos são capazes de apresentar formas polimórficas. O polimorfismo é a capacidade de uma molécula cristalizar em duas ou mais formas. Polimorfos diferentes de um mesmo fármaco podem apresentar diferenças significativas

\section{Figura 1}

Patente de seleção de derivados de piperazina.

PI 9201624
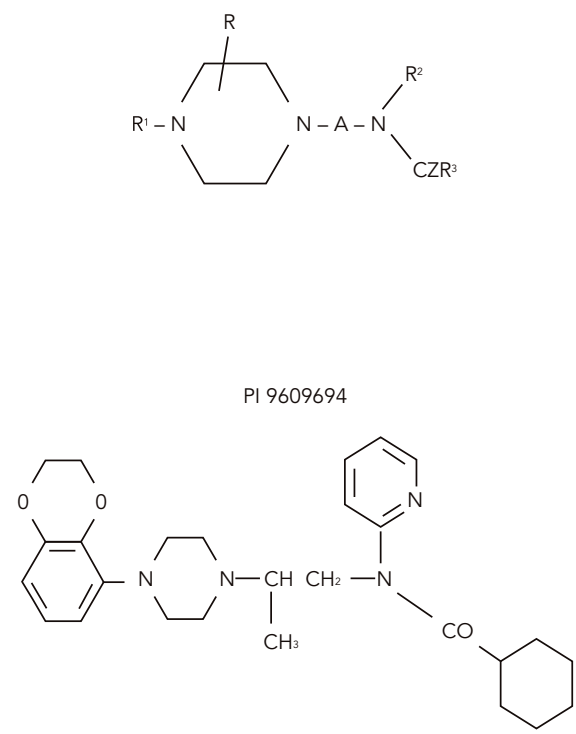
de solubilidade, processabilidade e estabilidade física e química. Essas diferenças físico-químicas irão alterar o comportamento da molécula em um meio biológico, inclusive modificando sua biodisponibilidade 50 .

A processabilidade de polimorfos refere-se às interações do fármaco com outros excipientes, verificada na etapa de pré-formulação de um novo medicamento e nas operações unitárias realizadas para fabricação do mesmo. Os polimorfos podem mudar de forma quando misturados a outras substâncias ou em determinadas etapas da fabricação do medicamento (p.ex.: moagem dos pós), alterando as características do fármaco e comprometendo a eficácia e segurança do produto acabado 51 .

Observam-se depósitos de patentes independentes nas quais são reivindicados produtos e processos de obtenção de polimorfos de fármacos conhecidos. Normalmente, a invenção reside em um novo processo de obtenção da droga visto que a patente original do fármaco, na qual este é definido por "grupo Markush", costuma proteger o princípio ativo como um todo. Exemplo de patente de polimorfo é o PI9610201 de forma cristalina de tazofelona.

As indústrias utilizam-se desse mecanismo de proteção. Contudo, é discutível se essas invenções não representariam uma forma de prorrogação da proteção sobre a invenção original. A Smithkline depositou uma patente de polimorfo da cimetidina aproximadamente cinco anos após a patente original ter sido concedida 37 .

As discussões técnicas do INPI para a construção das diretrizes de exame não chegaram ao consenso quanto aos requisitos mínimos que devem conter um pedido dessa tecnologia. O INPI informou, ao término desse ciclo de discussões, que existia um formato para consulta pública $38,39,40,41,42,43,44,45$, porém nenhuma proposta de diretriz foi disponibilizada.

\section{- Isômeros ópticos}

Os isômeros são substâncias compostas diferentes que possuem a mesma fórmula molecular. Estereoisômeros diferem somente no arranjo de seus átomos no espaço e são subdivididos em duas classes: enatiômeros e diasteroisômeros. Enantiômeros são estereoisômeros que são a imagem especular um do outro e ocorre em compostos cujas moléculas possuem centro quiral (um átomo de carbono ligado a quatro substituintes diferentes). Contrariamente, os diasteroisômeros não são a imagem especular entre si 52 .

Os enantiômeros possuem propriedades físicas (ponto de fusão, ponto de ebulição, densidade e outros) idênticas, mas diferem quanto ao comportamento frente à luz planopolarizada. Segundo a direção em que giram a luz planopolarizada são classificados em dextrógira (direção horária) e levógira (direção anti-horária). Misturas racêmicas ocorrem quando há a presença de dois enantiômeros.

A quiralidade, característica das moléculas que possuem pelo menos um centro quiral, fornece substâncias com perfis biológicos distintos evidenciando a importância de separação desses compostos. Como exemplo, a talidomida na configuração dextrógira possui efeito sedativo e hipnótico ao passo que a configuração levógira é teratogênica 53 .

O domínio da estereoseletivade para as indústrias farmacêuticas é indiscutível. O fármaco conhecido como clorazepato era vendido, até 1998 , por US\$ 11 cada frasco com 500 comprimidos do racemato. A empresa italiana Profarmaco passou a produzir um enantiômero puro desse princípio ativo e, hoje, esse medicamento é vendido por US\$377. O mesmo aconteceu com o lorazepam, cujo racemato é vendido por US\$ 7,30 e o enantiômero puro a US\$191,50, nos Estados Unidos 54

A separação de racematos e as reivindicações de medicamentos contendo apenas um dos enantiômeros estão dentre as táticas de Pesquisa \& Desenvolvimento aplicadas nas indústrias farmacêuticas. O PI9609694 é um exemplo específico desse estratagema.

\section{Combinações de fármacos}

As combinações de fármacos são caracterizadas pela presença de várias substâncias ativas em uma mesma unidade farmacotécnica. A Política Vigente para Regulamentação de Medicamentos no Brasil 55 define como associações racionais "aquelas em que há evidência de aumento de eficácia sem aumento de toxicidade".

Nas patentes, as combinações baseiam-se, normalmente, na união de fármacos descritos em documentos anteriores. A associação de invenções requer que o relacionamento entre características ou grupo de características seja de funcionalidade recíproca ou que mostre uma combinação de efeitos sobre a soma de efeitos individuais 32 , o que vai ao encontro das associações racionais que preconizam um aumento de eficácia

No caso de combinações que preenchem o requisito de novidade a discussão reside na atividade inventiva. Segundo a Corte de Recursos do EPO, esta análise deve considerar os seguintes fatores: se o estado da arte pode sugerir ou não a um técnico no assunto precisamente a combinação das características reivindicadas, uma 
vez que o fato de uma característica individual ou um número de características serem conhecidas não mostra conclusivamente a obviedade da combinação; se o técnico no assunto pode, de fato, ter realizado a invenção na expectativa de um melhoramento; e se o estado da arte pode ter levado o técnico no assunto a esta combinação específica de características 32 .

Um exemplo desse tipo de invenção é a associação dos anti-retrovirais Lamivudina e Zidovudina descrita nas patentes US5047407, US5859021, US5905082.

\section{Pró-drogas}

As pró-drogas são compostos químicos com baixa ou nenhuma atividade farmacológica que, quando biotransformados, tornam-se metabólitos terapêuticos ativos 56 . Em alguns pedidos de produtos farmacêuticos em que há a descrição do primeiro grupo de compostos, fórmulas do tipo "grupo Markush", tem sido observada a inclusão de reivindicações dependentes como “composto caracterizado pela fórmula X seus sais farmaceuticamente aceitáveis, a pró-droga deste composto ou deste sal, ou o solvato ou hidrato deste composto, deste sal ou pró-droga". Exemplo desse tipo de reivindicação pode ser observado no PI0409701-1.

Assim, o requerente da patente tenta ampliar o escopo de proteção da invenção para compostos ainda não explorados. As pró-drogas são obtidas por derivações químicas ou modificações em princípios ativos conhecidos para solucionar problemas técnicos. Dentre eles, Testa 57 destaca a baixa solubilidade da droga, instabilidade química e propriedades organolépticas inadequadas. Nota-se que a construção de uma pró-droga depende de pesquisa que, muito provavelmente, não está associada aos primeiros estágios de desenvolvimento de um produto farmacêutico no qual se busca apenas definir os compostos, via "grupo Markush", com potencial terapêutico.

\section{Patentes de 1ㅇ e 2o usos médicos}

As invenções relacionadas a substâncias ou composições que visam a proteger o uso no tratamento de determinadas doenças, segundo as diretrizes de exame do INPI, podem ser de dois tipos: um novo uso, como medicamento, de produto já conhecido com utilização fora do âmbito medicinal, dito primeiro uso médico; ou uma nova aplicação terapêutica de produto conhecido como medicamento, definido como segundo uso médico 46 .

O “1o uso médico" de um produto conhecido, no Brasil, não é permitido por não preencher o requisito de novidade 46 . Outros escritórios de patentes permitem esse uso, como o EPO. O artigo 54(5) da Convenção Européia de Patentes 32 estabelece que não se deve excluir a patenteabilidade de qualquer substância ou composição compreendida no estado da arte, para uso num método de tratamento no corpo humano ou animal e diagnósticos in vivo, contanto que o uso não esteja compreendido no estado da arte.

O primeiro uso médico prevê uma exceção à regra geral de antecipação de uma substância ou composição conhecida do estado da técnica uma vez que, na ausência do disposto no artigo 54(5), estes objetos não seriam patenteáveis por não preencherem o requisito de novidade 58 . Assim, a Corte de Recursos do EPO 32, no caso T128/82, concedeu à empresa Hoffman-La Roche o primeiro uso médico aos seus derivados de piperidina. A Corte entendeu que a aplicação medicinal de compostos antes empregados em outros campos tecnológicos deve ser considerada nova.

A concessão de patentes de "2o uso médico" iniciou-se em 1984 pelo EPO 37. Devido aos empecilhos do sistema de patentes para proteger novos formatos das pesquisas farmacêuticas, foi criado, dentro da Convenção Européia de Patentes, um meio de contornar esta problemática 24 para atender as demandas das indústrias. A solução para desvincular o uso de um método de tratamento foi atrelá-lo ao processo de fabricação do medicamento. As reivindicações do tipo "uso do produto X caracterizado por ser na preparação de um medicamento para tratar a doença $Y^{\prime \prime}$ ficaram conhecidas como "Fórmula Suíça”. Atualmente, este formato de reivindicação foi substituído para reivindicações de composto - "composto $X$ para uso no tratamento da doença $Y$ ” 59.

No Brasil, ainda vigora a "Fórmula Suíça". As discussões técnicas que visam a alterar as diretrizes de exame não definiram qual o tipo de reivindicação que será aceita para esta matéria. Todavia, houve uma proposta feita pelo INPI das características técnicas que devem ser verificadas para concessão dessas patentes. A novidade seria aferida por uma nova aplicação do produto farmacêutico conhecido, para tratar uma patologia e/ou um quadro clínico distinto do estado da técnica. A atividade inventiva seria observada por novo mecanismo de ação, relação atividade terapêutica estrutura-química do fármaco e etiologia das doenças alvo. Finalizando, o pedido estaria recoberto de suficiência descritiva se houvesse descrição de ensaios clínicos e testes experimentais in vivo associada aos testes in vitro $38,39,40,41,42,43,44,45$.

A concessão de patentes de "2o uso médico” não é harmônica entre os países. Argentina, 
Comunidade Andina e Índia não concedem proteção, ao passo que China, Estados Unidos, Japão e os países integrantes da Convenção Européia de Patentes consentem. Os motivos para impedir a concessão são distintos. Como aponta Correa ${ }^{37}$, as invenções de segundo uso médico de uma substância são consideradas não-patenteáveis porque este uso não satisfaz vários requisitos necessários a uma patente: trata-se de uma "descoberta”; não preenche o requisito de aplicação industrial; equivale-se a um método de tratamento; e a "Fórmula Suíça" recai sobre a objeção da falta de novidade, uma vez que normalmente o medicamento a ser preparado é o mesmo usado para a primeira indicação terapêutica. Os países que não aceitam as invenções de "2o uso médico" não concedem patentes por pelo menos um dos motivos mencionados.

No Escritório de Patentes do Reino Unido, por exemplo, o segundo uso médico foi categorizado de acordo com as decisões exaradas pela Corte de Apelação Européia que são sumarizadas na Tabela 2 .

Segundo Vasconcellos 26, já que o INPI concede patentes de segundo uso médico, este fato deve constituir uma oportunidade para proteção patentária das pesquisas de desenvolvimento de novos usos terapêuticos de moléculas oriundas da flora brasileira. Apesar da legislação nacional impedir a proteção de produtos isolados da natureza; quando o homem confere uso prático a estes produtos, o uso passa a ser patenteável. Essa flexibilidade possibilita participação mais efetiva dos inventores nacionais de fitofármacos e fitoterápicos na apropriação do conhecimento associado à biodiversidade.

Nos países em desenvolvimento, nos quais as capacidades de pesquisa são mais adequadas para explorar propriedades de fármacos existentes do que desenvolver novas entidades químicas, pode ser interessante conceder formas limitadas de exclusividade ou recompensas como incentivo a este tipo de investigação 48 .

No que concerne à LPI, o artigo 42 institui que a patente confere ao seu titular o direito de impedir terceiros, sem o seu consentimento, de produzir, usar, colocar à venda, vender ou importar com estes propósitos produto objeto de patente, e processo ou produto obtido diretamente por processo patenteado. A lei é silente quanto à proteção ao "uso", pois não prevê especificamente reivindicações desse tipo. Esse fato pode ser interpretado de duas formas: o artigo 42 define as categorias de reivindicações, conseqüentemente, reivindicações de uso estão inexplícitas e não seriam passíveis de privilégio; ou as definições do artigo em tela não são limitativas, tornando as reivindicações de uso privilegiáveis.

É importante advertir que a Diretoria Colegiada da ANVISA, em 25de agosto de 2004, por meio de uma nota técnica, considerou que o "novo uso" de substâncias "é lesivo à saúde pública, a desenvolvimento científico e tecnológico do pais, podendo dificultar o acesso da população aos medicamentos. Neste sentido, decidiu pela não concessão da anuência prévia a casos de pedidos de patentes de segundo uso" 59. Destarte, criou-se um impasse, pois independente do formato que o INPI adote para a análise e depósito de futuros pedidos de patentes concernentes à matéria, os mesmos não serão concedidos.

As patentes de "novos usos" reduzem o acesso a medicamentos quando os titulares das patentes originais utilizam-nas para bloquear a entrada de medicamentos genéricos e ampliar seu tempo de proteção 48 , o que, normalmente, ocorre no Brasil.

\begin{tabular}{lc}
\hline Privilegiável & Não-privilegiável \\
\hline - Uso de uma substância ou composição no & • Uso em termos do modo de administração, ou da \\
tratamento de uma nova doença ou condição & quantidade, freqüência, ou tempo de dosagem \\
específica previamente utilizada no tratamento de & • Reivindicação de novo mecanismo de ação ou diferente \\
uma doença distinta & efeito técnico para mesmo uso terapêutico conhecido do \\
- Novo grupo de pacientes tratados, a despeito do & estado da arte \\
fato da droga e da doença tratada terem sido & - Vantagem adicional não esperada em um tratamento \\
relacionadas no estado da técnica & conhecido
\end{tabular}




\section{Considerações finais}

A evolução da proteção patentária no setor farmacêutico aponta para ampliação do tempo de proteção por meio da redação de novas patentes em torno de fármacos descritos em fórmulas do tipo "grupo Markush". Patentes de seleção têm sido uma das principais facetas da estratégia de perpetuação da proteção patentária pelas indústrias farmacêuticas que, ao obterem maior número de patentes em torno de uma invenção original, maximizam as oportunidades de comercialização de produtos com inovações incrementais. O INPI parece mostrar uma tendência de acompanhamento dos mecanismos de análise de pedidos de patentes empregados por outros países desenvolvidos, onde se denota o estabelecimento de escopos de proteção mais permissivos quanto à proteção deste tipo de invenções.

Destaca-se que se por um lado as patentes de seleção podem servir como uma oportunidade tecnológica e comercial, por outro, a aceitação deste tipo de patente pode constituir uma ameaça a uma política de acesso a medicamentos. A reedição de patentes baseadas em um mesmo fármaco, como a concessão de polimorfos e enantiômeros puros, pode estender o tempo de monopólio sobre um determinado fármaco e retardar a entrada da versão genérica no mercado visto que, para que estes sejam comercializados, é necessário que as patentes às quais fazem referência estejam em domínio público.

Por outro lado, o desenvolvimento de invenções de menor custo como a construção de metoos, novas formas farmacêuticas, combinações de fármacos, pró-drogas e o 2o uso médico pode ser uma opção tática para países com capacidade tecnológica instalada como o Brasil. Sendo assim, conhecer os aspectos do patenteamento no setor farmacêutico é fundamental para que o país alcance maior desempenho na proteção de invenções neste campo tecnológico.

A inquetação quanto aos escopos de proteção das patentes farmacêuticas no mundo torna-se mais evidente face ao SPLT que propõe uma regulamentação e uma diretriz a ser adotada pelos países partícipes. Essas diretrizes, dentre outros aspectos, visam a harmonizar a interpretação dos requisitos de patenteabilidade sob a argumentação de que uma análise, para a concessão de pedidos de patente, mais uniforme entre os diversos países, traria maior segurança jurídica ao sistema de patentes. Contudo, o SPLT prevê obrigações que extrapolam o TRIPS, pois este determina apenas que as patentes, para serem concedidas, devem ser novas, inventivas e dotadas de aplicação industrial, não sendo especificado como os membros integrantes deste Acordo devem interpretar cada um destes requisitos, permitindo certa autonomia aos Escritórios de Patentes quanto à sua verificação.

A falta de parâmetros claros quanto à concessão de patentes traz incerteza para os investidores em pesquisa, desenvolvimento e inovação. Nesse sentido, especificamente no caso do Brasil, urge a definição das modalidades e formas de proteção de produtos e processos do setor farmacêutico, tanto pelo INPI quanto pela ANVISA, a fim de nortear os usuários do sistema de patentes - universidades, centros de pesquisas e empresas nacionais.

Além disso, estabelecer de maneira clara as modalidades e aspectos da proteção intelectual das criações no setor farmacêutico será um facilitador para que os elaboradores e gestores de políticas públicas de saúde possam antever as inovações que poderão ser ofertadas à população, e tomar decisões quanto à inclusão dessas novas terapias medicamentosas nos sistemas de saúde públicos a preços justos. 


\section{Resumo}

As formas de proteção das invenções no setor farmacêutico apontam para estratégias de perpetuação da proteção patentária. Com base em uma revisão bibliográfica mostrou-se as especificidades do patenteamento no setor, perpassando por um breve histórico sobre a concessão de patentes farmacêuticas no Brasil, uma abordagem sobre invenções patenteáveis e nãopatenteáveis, e pelas modalidades e aspectos da proteção patentária que visam à extensão do monopólio temporário conferido pela patente. Dentre essas estratégias estão as patentes direcionadas a polimorfos e isômeros ópticos de fármacos; combinações de fármacos e segundo uso médico, cada vez mais presentes nas reivindicações dos pedidos de privilégio de invenção das indústrias farmacêuticas. O objetivo do trabalho é mostrar algumas especificidades dos pedidos de patente farmacêuticas, de modo a contribuir para a formação de expertise na área e para a discussão sobre o impacto da ampliação dos escopos de proteção das patentes. Conclui-se que se por um lado a tendência de escopos de proteção mais permissivos pode desvelar oportunidades para os inventores nacionais, por outro, pode ser danosa para uma política de acesso a medicamentos.

Patentes de Medicamentos; Indústria Farmacêutica; Propriedade Intelectual

\section{Colaboradores}

A. H. L. Jannuzzi elaborou a versão preliminar e final do manuscrito. A. G. Vasconcellos contribuiu com o melhoramento da versão preliminar, inserção de comentários aos temas abordados e com a revisão final. C. G. Souza colaborou na revisão final do artigo.

\section{Referências}

1. Buainain AM, Carvalho SMP, Paulino SR, Yamamura S. Propriedade intelectual e inovação tecnológica: algumas questões para o debate atual. http://www.desenvolvimento.gov.br/arquivo/ secex/sti/indbrasopodesafios/coletanea/ofuti ndcadprodutiva/AntonioMarcio.pdf (acessado em 10/Jul/2007).

2. Markman GD, Espina MI, Phan PH. Patents as surrogates for inimitable and non-substitutable resources. Journal of Management 2004; 30:529-44.

3. Maldonado J. Tecno-globalismo e acesso ao conhecimento. In: Lastres HMM, Albagli S, organizadores. Informação e globalização na era do conhecimento. Rio de Janeiro: Editora Campus; 1999. p. 105-21.

4. Angell M. A verdade sobre os laboratórios farmacêuticos. Rio de Janeiro: Editora Record; 2007.

5. St-Onge J-C. O outro lado da pílula ou os bastidores da indústria farmacêutica. http://www. ensp.fiocruz.br/eventos_novo/dados/arq3257.doc (acessado em 07/Fev/2008).

6. Binns R, Driscoll B. Intellectual property issues in R\&D contracts. Pharm Sci Technol Today 1998; 1:95-9.

7. Buainain AM, Carvalho SMP. Propriedade intelectual em um mundo globalizado. Parcerias Estratégicas 2000; 9:145-53.

8. Albuquerque EM. Empresas transnacionais e suas patentes no Brasil: resultados iniciais de uma investigação sobre a internacionalização de atividades tecnológicas. Revista de Economia Contemporânea 2000; 4:85-111.

9. Grabowski H. Patents, innovation and access to new pharmaceuticals. Journal of International Economic Law 2002; 5:849-60.

10. Reis ALA, Bermudez J. Aspectos econômicos: mercado farmacêutico e preços de medicamentos. In: Bermudez JAZ, Oliveira MA, Esher A, organizadores. Acesso a medicamentos. Rio de Janeiro: Escola Nacional de Saúde Pública, Fundação Oswaldo Cruz; 2004. p. 139-55.

11. Reis ALA, Bermudez J, Oliveira MA. Effects of the TRIPS Agreement on the access to medicines: considerations for monitoring drug prices. In: Bermudez J, Oliveira MA, organizadores. Intellectual property in the context of the WTO TRIPS agreement: challenges for public health. Rio de Janeiro: Escola Nacional de Saúde Pública, Fundação Oswaldo Cruz; 2004. p. 99-115.

12. Brasil. Lei no. 10.973. Dispões sobre incentivos à inovação e à pesquisa científica e tecnológica no ambiente produtivo e dá outras providências. Diário Oficial da União 2004; 2 dez.

13. Brasil. Lei no. 5.772. Institui o novo Código da Propriedade Industrial. Diário Oficial da União 1971; $21 \mathrm{dez}$.

14. Brasil. Lei no. 9.279. Regula direitos e obrigações relativos à propriedade industrial. Diário Oficial da União 1996; 14 mai.

15. Brasil. Decreto no. 1.355. Promulga a ata final que incorpora os resultados da Rodada Uruguai de Negociações Comerciais Multilaterais do GATT. Diário Oficial da União 1994; 30 dez. 
16. Jannuzzi AHL. Proteção patentária de medicamentos no Brasil: avaliação dos depósitos de patente de invenção sob a vigência da nova lei de propriedade industrial (9.279/96) [Dissertação de Mestrado]. Rio de Janeiro: Centro Federal de Educação Tecnológica Celso Suckow da Fonseca; 2007.

17. Barbosa DB. Uma introdução à propriedade industrial. Rio de Janeiro: Editora Lumen Júris; 2003.

18. Brasil. Lei no. 10.196. Altera e acresce dispositivos à Lei no. 9.279, de 14 de maio de 1996, e regulamenta direitos e obrigações relativos à propriedade industrial, e dá outras providências. Diário Oficial da União 2001; 14 fev.

19. Associação Brasileira de Propriedade Intelectual. Resolução no. 2, de 27/01/2000. http://www.abpi. org.br/bibliotecas.asp?idiomas=Português\&secao $=$ Resoluções $\% 20 \mathrm{da} \% 20 \mathrm{ABPI} \&$ codigo=3\&resolucao $=68$ (acessado em 23/Jan/2008).

20. Brasil. Decreto no. 75.572. Promulga a Convenção de Paris para a Propriedade Industrial, Revisão de Estocolmo, 1967. Diário Oficial da União 1975; 10 abr.

21. Associação Brasileira de Propriedade Intelectual. Resolução no. 16, de 12/09/2001. http://www.abpi. org.br/bibliotecas.asp?idiomas=Português\&secao =Resoluções\%20da\%20ABPI\&codigo=3\&resolucao $=53$ (acessado em 23/Jan/2008).

22. Barbosa DB. A inconstitucionalidade da anuência da ANVISA no procedimento de concessão de patentes como manifestação discricionária da Administração Federal. http://denisbarbosa.addr.com/ anuencia.doc (acessado em 23/Jan/2008).

23. Oliveira MA, Bermudez JAZ, Osorio-de-Castro CGS. Assistência farmacêutica e acesso a medicamentos. Rio de Janeiro: Editora Fiocruz; 2007.

24. Correa C. Guidelines for the examination of pharmaceutical patents: developing a public heath perspective. Geneva: World Health Organization; 2007.

25. Vasconcellos AG. Propriedade intelectual dos conhecimentos associados ao estudo das plantas medicinais: desafio para gestão autônoma da biodiversidade brasileira. In: Ming LC, Carvalho I, Vasconcellos MC, Radomski MI, Costa MAG, organizadores. Direitos de recursos tradicionais: formas de proteção e repartição de benefícios. Botucatu: Editora Unesp; 2005. p. 21-45.

26. Vasconcellos AG. Propriedade intelectual dos conhecimentos associados à biodiversidade, com ênfase nos derivados de plantas medicinais - desafios para inovação biotecnológica no Brasil [Tese de Doutorado]. Rio de Janeiro: Centro de Ciências da Saúde, Universidade Federal do Rio de Janeiro; 2003.

27. Macedo MFG, Müller ACA, Moreira AC. Patenteamento em biotecnologia. Brasília: Editora Embrapa; 2001.

28. Adcock M, Llewelyn M. Micro-organisms, definitions and options under TRIPS. Geneva: Quaker United Nations Office; 2000. (Occasional Paper, 2).

29. World Intellectual Property Organization. Substantive patent law treaty. http://www.wipo.int/ patent/law/en/harmonization.htm (acessado em 27/Jul/2007).
30. Simmons ES. The grammar of Markush structure searching: vocabulary vs. syntax. J Chem Inf Comput Sci 1991; 31:45-53.

31. Beuzekom B, Arundel A. OECD biotechnology statistics-2006. http://www.oecd.org/datao ecd $/ 51 / 59 / 36760212$.pdf\#search $=\% 22$ OECD $\% 20 \mathrm{~B}$ iotechnology\%20Statistics-2006\%22 (acessado em 27/Set/2006).

32. European Patent Office. Guidelines for examination in the EPO. Munich: European Patent Office; 2001.

33. Ministério do Meio Ambiente. Política nacional da biodiversidade. Decreto no. 4.339, de 22/08/2002. http://ftp.mct.gov.br/temas/biodiversidade/docu mentos/Dec_4339.pdf (acessado em 10/Jan/2007).

34. Simões CMO, Schenkel EP. A pesquisa e a produção brasileira de medicamentos a partir de plantas medicinais. Rev Bras Farmacogn 2002; 12:35-40.

35. United States General Accounting Office. NHIprivate sector partnership in the development of taxol. http://www.gao.gov/new.items/d03829.pdf (acessado em 16/Abr/2008).

36. Teece DJ. Managing intellectual capital: organizational, strategic, and policy dimensions. Oxford: Oxford University Press; 2002.

37. Correa C. Integrating public health concerns into patent legislation in developing countries. http:// www.idlo.int/texts/IDLO/mis3649.pdf (acessado em 30/Jul/2006).

38. Instituto Nacional da Propriedade Industrial. 2o uso médico. http://www.inpi.gov.br (acessado em 24/Jan/2008).

39. Instituto Nacional da Propriedade Industrial. Ata completa da 1a reunião do grupo de estudos sobre segundo uso médico. http://www.inpi.gov.br (acessado em 24/Jan/2008).

40. Instituto Nacional da Propriedade Industrial. Ata da 2 a reunião do grupo de estudos sobre segundo uso médico. http://www.inpi.gov.br (acessado em 24/Jan/2008).

41. Instituto Nacional da Propriedade Industrial. Ata da 3a reunião do grupo de estudos sobre segundo uso médico. http://www.inpi.gov.br (acessado em 24/Jan/2008).

42. Instituto Nacional da Propriedade Industrial. Diretrizes para o exame de pedidos de patentes na área de segundo uso médico. http://www.inpi.gov. br (acessado em 24/Jan/2008).

43. Instituto Nacional da Propriedade Industrial. 2a reunião do grupo de estudos sobre polimorfismo (resumo). http://www.inpi.gov.br (acessado em 24/Jan/2008).

44. Instituto Nacional da Propriedade Industrial. 3a reunião do grupo de estudos sobre polimorfismo. http://www.inpi.gov.br (acessado em 24/ Jan/2008).

45. Instituto Nacional da Propriedade Industrial. Errata da ata de reunião de patenteabilidade de formas polimórficas realizada em 12/06/2007. http:// www.inpi.gov.br (acessado em 24/Jan/2008).

46. Instituto Nacional da Propriedade Industrial. Diretrizes para o exame de pedidos de patente nas áreas de biotecnologia e farmacêutica depositados após 31/12/1994. Revista da Propriedade Intelectual 2002; 6 ago. 
47. European Patent Office. International academy seminar on examination in the field of pharmaceuticals. Munich: European Patent Office; 2000.

48. Correa CM, Shabalala D. Salud pública y patentes farmacéuticas: segundos usos. In: Rodrigues Junior EB, Polido F, organizadores. Propriedade intelectual. Rio de Janeiro: Editora Elsevier; 2007. p. 153-81.

49. Scholze SHC. Os direitos de propriedade intelectual e a biotecnologia. Cadernos de Ciência \& Tecnologia 1998; 15(N Esp):41-66.

50. Aguiar MRMP, Gemal AL, Gil RAS. Caracterização de polimorfismo em fármacos por ressonância magnética nuclear no estado sólido. Química Nova $1999 ; 22: 553-64$.

51. Brandão ALA. Influência do polimorfismo na fabricação de cápsulas no setor magistral. http://www. intecq.com.br/docs/publicacoes/Polimorfismo\% $20 \mathrm{e} \% 20$ Farmacocin\%C3\%A9tica.pdf (acessado em 28/jan/2008).

52. Solomons TWG. Química orgânica. Rio de Janeiro: Livros Técnicos e Científicos Editora; 1982.

53. Bermudez JAZ, Barragat P. Medicamentos quirais: da dimensão química à discussão política. Cad Saúde Pública 1996; 12:47-51.
54. Universidade Federal de Santa Catarina. Drogas quirais. http://www.qmc.ufsc.br/qmcweb/exemplar23.html (acessado em 08/Set/2006).

55. Agência Nacional de Vigilância Sanitária. Política vigente para a regulamentação de medicamentos no Brasil. http://www.anvisa.gov.br/medica mentos/manual_politica_medicamentos.pdf (acessado em 02/Jul/2007).

56. Testa B. Prodrug research: futile or fertile? Biochem Pharmacol 2004; 68:2097-106.

57. UK Intellectual Property Office. Examination guidelines for patent applications relating to medical inventions in the UKPO. London: UK Intellectual Property Office; 2004.

58. Rocha FR. Patentes de segundo uso. http://www. inpi.gov.br/menu-esquerdo/patente/discussoestecnicas/segundo-uso-medico (acessado em 25/ Jan/2008)

59. Agência Nacional de Vigilância Sanitária. Esclarecimentos sobre pedidos de patentes dos produtos e processos farmacêuticos. http://www.anvisa.gov. $\mathrm{br} /$ divulga/informes/2004/250804.htm (acessado em 23/Jan/2008).

Recebido em 13/Set/2007

Versão final reapresentada em 21/Fev/2008 Aprovado em 28/Fev/2008 